\title{
An international survey on recognition and characterization of atrophic gastritis and intestinal metaplasia
}

\section{다)(요 $\odot$}

\author{
Authors \\ Enders Kwok Wai $\mathbf{N g}^{1}$

\section{Institutions} \\ 1 Division of Upper GI and Metabolic Surgery, Department \\ of Surgery, Prince of Wales Hospital, the Chinese \\ University of Hong Kong, Hong Kong \\ 2 Department of Gastrointestinal Oncology, Osaka \\ International Cancer Institute, Osaka, Japan
}

Hon Chi Yip ${ }^{1}$, Noriya Uedo ${ }^{2}$, Shannon M. Chan ${ }^{1}$, Anthony Yuen Bun Teoh ${ }^{1}$, Simon Kin Hung Wong ${ }^{1}$, Philip W. Chiu

submitted 5.4.2020

accepted after revision 28.5 .2020

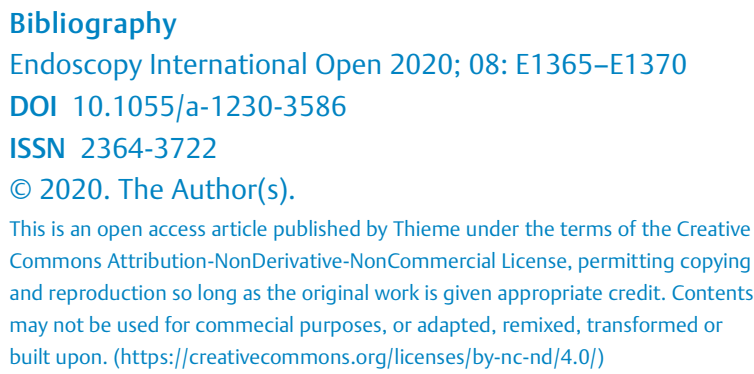
Commons Attribution-NonDerivative-NonCommercial License, permitting copying and reproduction so long as the original work is given appropriate credit. Contents may not be used for commecial purposes, or adapted, remixed, transformed or built upon. (https://creativecommons.org/licenses/by-nc-nd/4.0/)

Corresponding author

Hon Chi Yip, Chinese University of Hong Kong Faculty of Medicine - Department of Surgery, 4/F, Lui Che Woo Clinical Sciences Building, Prince of Wales Hospital, Hong Kong New Territories, Hong Kong, China

Fax: +852 26377974

hcyip@surgery.cuhk.edu.hk

\section{ABSTRACT}

Background and study aims Atrophic gastritis (AG) and intestinal metaplasia (IM) are premalignant conditions of gastric cancer and endoscopic recognition and characterization may help in stratifying the gastric cancer risk for screening and surveillance. However, there is currently lack of consensus in defining the severity of AG and IM. We aimed to conduct an international survey to understand the current practice of endoscopists worldwide.

Methods An online survey was designed to collect data regarding participants' practice in endoscopic assessment of AG \& IM. A test using images was conducted to evaluate the difference in accuracy of characterization of AG \& IM.

Results From July to October 2017, 249 endoscopists responded to the survey. Around $70 \%$ of participants received some form of training on recognition of AG \& IM. There was significant variety in the training received across different continents. One hundred seventy-six participants (70\%) would document the presence of both AG and IM, but the classification systems used were inconsistent between endoscopists. Overall accuracy in diagnosis of AG \& IM in the image test was $84.5 \%$ and $80.7 \%$ respectively. The diagnostic accuracy was significantly higher among Japanese and Korean endoscopists compared to the rest of the world. Conclusion Training regarding endoscopic recognition of AG \& IM differs significantly in different parts of the world. The difference in diagnostic accuracy for these premalignant gastric conditions may also explain the discrepancy in the early cancer detection rates among different countries. A simple unified classification system may be beneficial for better stratification of cancer risks.

\section{Introduction}

Gastric cancer is a significant medical disease worldwide, ranking fifth in cancer incidence and third in mortality around the globe [1]. When diagnosed and treated at an early stage, gastric cancer carries a significantly better overall survival. In countries where a high proportion of early gastric cancers are detected, a higher incidence:mortality ratio is observed. Unfortunately, the proportion of cases diagnosed early remains low in most areas outside of Japan and Korea. A study reporting outcomes in patients undergoing gastrectomy for gastric cancers found that only 205 of cancers were found at an early stage in the United States and versus $50 \%$ in Japan [2]. Population screening programs are well established in countries with the highest incidence of cancer, allowing for earlier cancer detection. In medium to low incidence regions, population screening is not a cost-effective strategy. Screening and surveillance of 


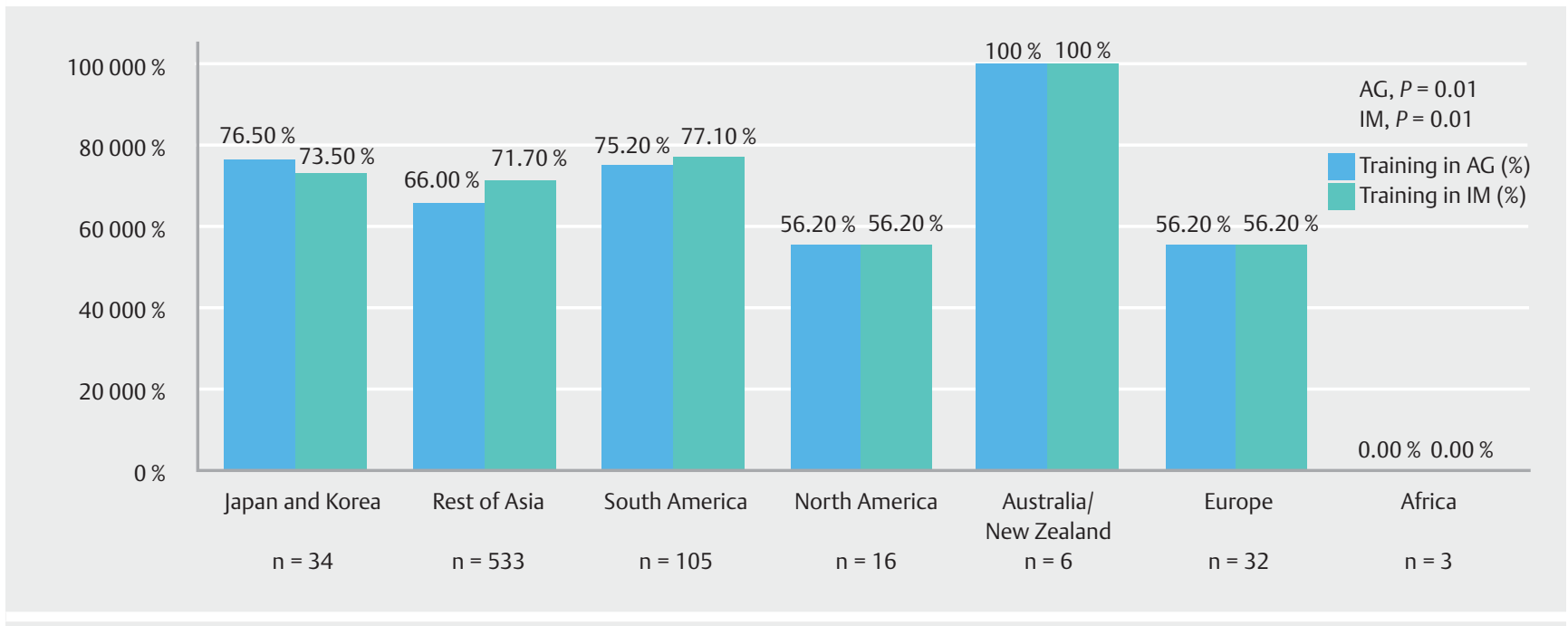

- Fig. 1 Proportion of participants with prior training in AG or IM.

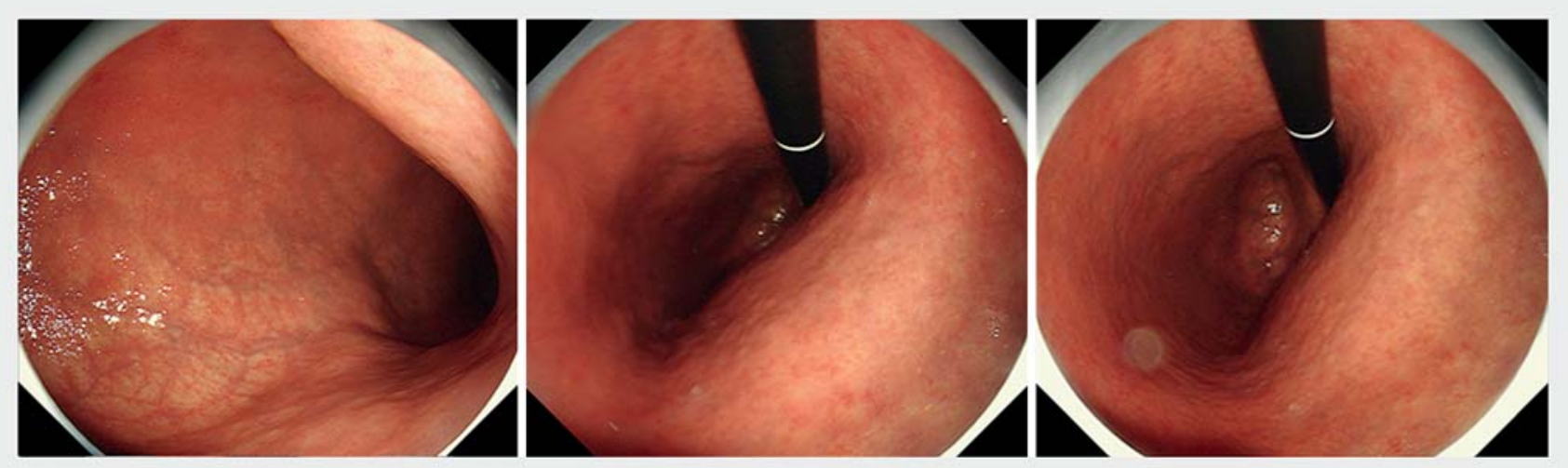

- Fig. 2 Sample question 1 in the picture test. "What is the degree of atrophic gastritis?" Answer-Severe atrophic gastritis (Open type II or III).

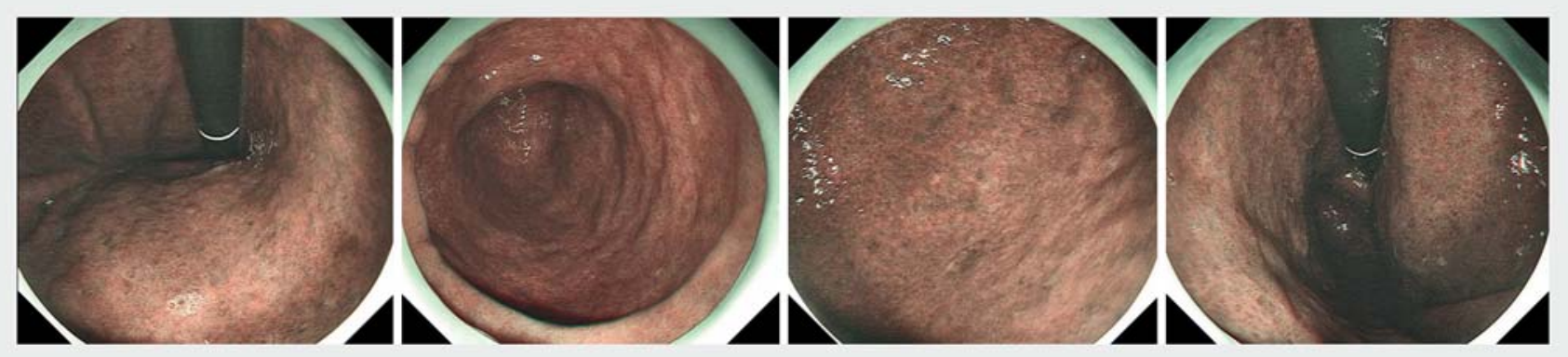

Fig. 3 Sample question 2. "What is the degree of intestinal metaplasia?" Answer-Extensive intestinal metaplasia involving corpus and antrum.

high-risk individuals has been recommended in the latest European guidelines [3].

Atrophic gastritis (AG) and intestinal metaplasia (IM) are established risk factors for gastric carcinogenesis [4]. However, there is currently lack of a standard in documenting the degree of atrophy and intestinal metaplasia. Endoscopic grading and histological grading have both been used occasionally in differ- ent countries [5-10]. In this study, we aimed to investigate current practice and training in terms of endoscopic assessment of AG and IM. 


\section{Methods}

The study was designed as an online survey using Internet software Google Form (https://goo.gl/forms/nHqusNiZsHS$\mathrm{n} 72 \mathrm{eN2}$ ). The questionnaire consisted of 1) basic demographics; 2) endoscopists' current situation in diagnosis and characterization of AG and IM; and 3) a an image test for endoscopic diagnosis of $A G$ and IM.

Information regarding participants' basic demographics was collected, including age, gender, type of hospital, years of experience as a medical doctor, number of diagnostic endoscopies per week, and country of practice. Data on endoscopists' current practice on diagnosis and characterization of AG and $\mathrm{IM}$, reporting of endoscopic findings, classification system used for AG, reporting on distribution of IM and biopsy protocol for diagnosis of AG or IM also were collected. Specific questions were asked about the endoscopists' prior education on diagnosis and characterization of AG and IM.

Finally, an image test consisting of seven cases (Helicobacter pylori-naïve normal patients, $\mathrm{n}=3$; patients with $\mathrm{AG}$ and $\mathrm{IM}, \mathrm{n}=$ 4) with endoscopic images of the stomach was used to assess participants' ability to recognize the severity of AG and IM. Examples of the questions are shown in > Fig. 1 and > Fig. 2 . Three questions were about the diagnosis and grading of gastric atrophy and four questions were about the diagnosis and grading of IM ( $>$ Fig. 3 ). In the four questions on IM, endoscopic images with narrow band imaging were provided for the participants' assessment. Two of the cases had severe AG visualized on the still images by pale-colored mucosa, increased visibility of submucosal vasculatures, and loss of gastric folds that involved the entire corpus of the stomach including the lesser and greater curvature. Two of the cases had significant IM involving both the antrum and corpus, as observed in the still images with multiple ridged/tubular epithelium and light blue crest sign in all parts of the stomach.

The questionnaire was sent out to endoscopists around the world through e-mail by the authors (H.Y. and N.U.). Recipients were encouraged to invite colleagues at any level of training with prior experience in upper gastrointestinal endoscopy to participate in the online survey.

Results from the online questionnaire were collected and analyzed. The difference in endoscopic practice between endoscopists from different parts of the world was assessed. The accuracy in endoscopic assessment of GA was also compared. In particular, comparison was made between endoscopists in Japanese and Korea, where a high proportion of early gastric cancers are detected, versus the rest of the participating endoscopists around the world. Continuous data were analyzed with the student's $t$-test or Mann Whitney $U$ test while categorical data were analyzed with $X^{2}$ test. Data analysis was performed with IBM SPSS statistics ver. 19.

\section{Results}

From July to October 2017, 249 endoscopists responded to the survey. Demographic information on the participants is shown in $>$ Table1. The majority of them had $>15$ years experience in
- Table 1 Background information on participating endoscopists.

\begin{tabular}{|c|c|}
\hline & Total \\
\hline \multicolumn{2}{|l|}{ Age } \\
\hline - 20-30 & $20(8.0 \%)$ \\
\hline - $30-35$ & $37(14.9 \%)$ \\
\hline - $35-40$ & $53(21.3 \%)$ \\
\hline . $>40$ & $139(55.8 \%)$ \\
\hline \multicolumn{2}{|l|}{ Gender } \\
\hline - Male & $190(76.3 \%)$ \\
\hline - Female & $59(23.7 \%)$ \\
\hline \multicolumn{2}{|l|}{ Type of hospital at work } \\
\hline - University affiliated hospital & $109(43.8 \%)$ \\
\hline - General Hospital & $73(29.3 \%)$ \\
\hline - Cancer center & $23(9.2 \%)$ \\
\hline - Private clinic & $40(16.1 \%)$ \\
\hline - Others & $4(1.6 \%)$ \\
\hline \multicolumn{2}{|l|}{ Years of experience } \\
\hline - $0-2$ & $17(6.8 \%)$ \\
\hline - $2-5$ & $41(16.5 \%)$ \\
\hline - 5-10 & $51(20.5 \%)$ \\
\hline - $10-15$ & $41(16.5 \%)$ \\
\hline$\cdot>15$ & $99(39.8 \%)$ \\
\hline \multicolumn{2}{|c|}{ Number of diagnostic endoscopy per week } \\
\hline - $0-10$ & $43(17.3 \%)$ \\
\hline - $10-20$ & $95(38.2 \%)$ \\
\hline - $20-50$ & $81(32.5 \%)$ \\
\hline . $>50$ & $30(12.0 \%)$ \\
\hline \multicolumn{2}{|l|}{ Countries of practice } \\
\hline - Japan and Korea & $34(13.7 \%)$ \\
\hline - Rest of Asia & $56(21.3 \%)$ \\
\hline - Europe & $32(12.9 \%)$ \\
\hline - North America & $16(6.4 \%)$ \\
\hline - South America & $105(42.2 \%)$ \\
\hline - Australia/New Zealand & $6(2.4 \%)$ \\
\hline - Africa & $3(1.2 \%)$ \\
\hline
\end{tabular}

endoscopy and worked in a university-affiliated hospital. More than $75 \%$ of the participants with the highest incidence of gastric cancer came from Asia and South America.

In our study, 69.5\% (173/249) and $71.1 \%$ (177/249) of endoscopists received prior training regarding endoscopic diagnosis of AG and IM, respectively. Only $30.5 \%$ of them received such training within the first or second year of their endo- 
- Table2 Current practice in assessment and reporting of AG \& IM.

\begin{tabular}{|c|c|c|c|c|}
\hline & All $(n=249)$ & Japan \& Korea $(n=34)$ & Rest of world $(n=215)$ & $P$ value \\
\hline \multicolumn{4}{|c|}{ Report on endoscopic finding of AG \& IM } & \multirow[t]{5}{*}{0.000} \\
\hline - Both AG and IM & $176(70.7 \%)$ & $18(52.9 \%)$ & $158(73.5 \%)$ & \\
\hline - AG only & $42(16.9 \%)$ & $15(44.1 \%)$ & $27(12.6 \%)$ & \\
\hline - IM only & $12(4.8 \%)$ & 0 & $12(5.6 \%)$ & \\
\hline - None & $19(7.6 \%)$ & $1(2.9 \%)$ & $18(8.4 \%)$ & \\
\hline \multicolumn{4}{|c|}{ Classification system used for AG } & \multirow[t]{6}{*}{0.000} \\
\hline - Kimura-Takemoto & $57(22.9 \%)$ & $32(94.1 \%)$ & $25(11.6 \%)$ & \\
\hline - Kyoto classification & $11(4.4 \%)$ & $2(5.9 \%)$ & $9(4.2 \%)$ & \\
\hline - OLGA & $81(32.5 \%)$ & 0 & $81(37.7 \%)$ & \\
\hline - Others & $19(7.6 \%)$ & 0 & $19(8.8 \%)$ & \\
\hline - None & $81(32.5 \%)$ & 0 & $81(37.7 \%)$ & \\
\hline \multicolumn{4}{|c|}{ Report on distribution of IM } & \multirow[t]{4}{*}{0.001} \\
\hline - Yes & $151(60.6 \%)$ & $12(35.3 \%)$ & $142(64.7 \%)$ & \\
\hline - No & $54(21.7 \%)$ & $15(44.1 \%)$ & $39(18.1 \%)$ & \\
\hline - Maybe & $44(17.7 \%)$ & $7(20.6 \%)$ & $37(17.2 \%)$ & \\
\hline \multicolumn{4}{|c|}{ Biopsy for diagnosis of AG or IM } & \multirow[t]{4}{*}{0.000} \\
\hline - Yes & $178(71.5 \%)$ & $3(8.8 \%)$ & $175(81.4 \%)$ & \\
\hline - No & $34(13.7 \%)$ & $26(76.5 \%)$ & $8(3.7 \%)$ & \\
\hline - Maybe & $37(14.9 \%)$ & $5(14.7 \%)$ & $32(14.9 \%)$ & \\
\hline \multicolumn{4}{|c|}{ Number of biopsies taken } & \multirow[t]{7}{*}{0.000} \\
\hline .0 & $30(12.0 \%)$ & $24(74.2 \%)$ & $6(2.8 \%)$ & \\
\hline .1 & $22(8.8 \%)$ & $4(12.9 \%)$ & $18(8.4 \%)$ & \\
\hline .2 & $44(17.7 \%)$ & $4(12.9 \%)$ & $40(18.6 \%)$ & \\
\hline .3 & $23(9.2 \%)$ & $1(2.9 \%)$ & $22(10.2 \%)$ & \\
\hline .4 & $47(18.9 \%)$ & 0 & $47(21.9 \%)$ & \\
\hline .5 & $83(33.3 \%)$ & $1(2.9 \%)$ & $82(38.1 \%)$ & \\
\hline
\end{tabular}

- Table 3 Accuracy in endoscopic diagnosis and severity assessment of AG and IM.

\begin{tabular}{|c|c|c|c|c|}
\hline & Overall & Japan and Korea & Others & $P$ value \\
\hline Diagnosis of AG & $84.5 \pm 14.8 \%$ & $92.7 \pm 13.1 \%$ & $83.2 \pm 14.7 \%$ & 0.001 \\
\hline Diagnosis of IM & $80.7 \pm 20.8 \%$ & $91.1 \pm 14.9 \%$ & $79.0 \pm 21.2 \%$ & 0.002 \\
\hline Severity of AG \& IM & $62.5 \pm 17.6 \%$ & $73.5 \pm 20.8 \%$ & $60.8 \pm 16.4 \%$ & 0.000 \\
\hline
\end{tabular}

scopic careesr. A significant variation was observed regarding their training around the globe ( $\mathbf{F i g} . \mathbf{2}$ ).

Most endoscopists would routinely report the presence of AG and IM (70.7\%) (ฉ Table 2). The classification systems being used for documenting degree of AG differed in different areas.
More than $90 \%$ of Japanese and Korean endoscopists would use the Kimura-Takemoto classification while $51.4 \%$ of South American and $43.8 \%$ of European would use the Operative Link for Gastritis Assessment (OLGA) system. Up to $56.6 \%$ of other Asian endoscopists and $75.0 \%$ of North American endoscopists 
had not been using any classification at all. As expected, $76 \%$ of Japanese and Korean endoscopists would not biopsy to confirm AG or IM while $81.4 \%$ of the rest of the endoscopists would biopsy. However, the number of biopsies to be taken significantly varied among the participants. For non-Japanese and non-Korean endoscopists, $60.0 \%$ of them would take four to five biopsies during upper endoscopy, following the updated Sydney system (or modified Sydney system omitting the incisura biopsy), while only $2.9 \%$ of Japanese and Korean endoscopists would take similar number of biopsies.

Overall accuracy (SD) in endoscopic diagnosis of AG \& IM in the image test was $84.5 \pm 14.8 \%$ and $80.7 \pm 20.8 \%$, respectively ( $\triangleright$ Table 3 ). The diagnostic accuracy for both AG and IM was significantly higher among Japanese and Korean endoscopists compared to the others (AG, $92.7 \pm 13.1 \%$ vs. $83.2 \pm 14.7 \%, P=$ 0.001 ; IM, $91.1 \pm 14.9 \%$ vs $79.0 \pm 21.2 \%, P=0.002$ ). Endoscopic assessment of the severity of AG \& IM was less accurate at 62.5 $\pm 17.6 \%$. The accuracy of Japanese and Korean endoscopists was still significantly higher $(73.5 \pm 20.8 \%$ vs $60.8 \pm 16.4 \%, P=$ 0.000).

\section{Discussion}

In the present study, we demonstrated that there is a wide variety in practices around the globe in detection and grading of the severity of AG and IM. Because these conditions are established as known precursors to gastric cancer, it is desirable to develop a more structured diagnostic approach.

Appreciating the degree of atrophy and intestinal metaplasia may help predict the risk of gastric cancer in a patient. Traditionally, the western endoscopic community has been using the OLGA and operative link on gastric intestinal metaplasia assessment (OLGIM) systems to stage the severity of AG and IM, as pathological assessment is still considered the gold standard [3]. In many Asian countries, endoscopy-based assessment such as the Kyoto and Kimura-Takemoto classifications is used. The results of our study echoed the difference in practice. In addition, it also showed that one-third of endoscopists did not routinely report on the severity of AG. That may reflect a current lack of systematic education for these conditions in different parts of the world.

There are a few theoretical benefits of real-time endoscopic assessment of AG and IM. First of all, immediate risk stratification could be performed, allowing the endoscopist to perform more prolonged, vigilant examination of the stomach if significant AG or IM is identified. Second, it may reduce the number of biopsies required for each endoscopic procedure, thus reducing the cost and potential complication from biopsies. Third, the Sydney classification of gastritis was based on random biopsies for determination of histological atrophy and intestinal metaplasia [11]. It may induce sampling error as the pattern of AG and IM are often patchy inside the stomach.

Kono et al previously reported a good correlation between endoscopic assessment of GA using the Kimura Takemoto classification and histopathological assessment in a mixed group of Japanese and western population [12]. Moreover, use of imageenhanced endoscopy has significantly improved endoscopic detection of premalignant gastric conditions. Features such as the light blue crest (LBC) sign and white opaque substances (WOS) are high accurate in diagnosing IM $[13,14]$. It may also help to map the severity of IM throughout the stomach. Recently, a new Endoscopic grading of gastric intestinal metaplasia (EGGIM) classification based on endoscopic assessment of IM has been reported [8]. The endoscopy- based "EGGIM" system has been found to have excellent correlation with the OLGIM histology-based system. More confirmatory studies are required but the current trend favors use of endoscopy-based assessment as a replacement for multiple gastric biopsies.

The accuracy of endoscopy-based assessment is highly dependent on the experience of the endoscopist. In our study, the ability to accurately diagnose and map premalignant gastric conditions varied between continents. Japanese endoscopists have been using endoscopic grading methods for a long time, thus their performance is understandably better than the rest of the world. It is essential that all endoscopists performing gastroscopy are equipped with adequate techniques and knowledge for assessing the severity of AG and IM before worldwide adoption of an endoscopic classification system for risk stratification.

Our study had several limitations. First, the number of endoscopists recruited was small and most were connected to university-affiliated or specialist cancer hospitals. The realworld situation may be even more variable than was demonstrated in the study. Second, in the image test, the endoscopic cases were chosen and validated by two endoscopists with vast experience in endoscopic recognition of GA and IM, but biopsy was not taken for confirmation, based on local practice. Although the most representative still images were provided in the image test, the lack of a continuous video may also have limited the participants' ability to assess the extent of AG and IM.

\section{Conclusion}

In conclusion, there is currently a wide variety of practice in diagnosing and grading GA and IM. Endoscopic evaluation and mapping of premalignant gastric conditions has not been widely adopted, and the diagnostic ability of endoscopists should be further improved through structured training and education.

\section{Acknowledgements}

The authors are grateful to all the doctors who participated in this questionnaire survey.

\section{Competing interests}

The authors declare that they have no conflict of interest. 


\section{References}

[1] Bray F, Ferlay J, Soerjomataram I et al. Global cancer statistics 2018: GLOBOCAN estimates of incidence and mortality worldwide for 36 cancers in 185 countries. CA Cancer J Clin 2018; 68: 394-424

[2] Noguchi Y, Yoshikawa T, Tsuburaya A et al. Is gastric carcinoma different between Japan and the United States? Cancer 2000; 89: 22372246

[3] Pimentel-Nunes P, Libanio D, Marcos-Pinto R et al. Management of epithelial precancerous conditions and lesions in the stomach (MAPS II): European Society of Gastrointestinal Endoscopy (ESGE), European Helicobacter and Microbiota Study Group (EHMSG), European Society of Pathology (ESP), and Sociedade Portuguesa de Endoscopia Digestiva (SPED) guideline update 2019. Endoscopy 2019; 51: 365-388

[4] Correa P. Human gastric carcinogenesis: a multistep and multifactorial process - First American Cancer Society Award Lecture on Cancer Epidemiology and Prevention. Cancer Res 1992; 52: 6735-6740

[5] Rugge M, Meggio A, Pennelli $G$ et al. Gastritis staging in clinical practice: the OLGA staging system. Gut 2007; 56: 631-636

[6] Kamada T, Haruma K, Inoue K et al. [Helicobacter pylori infection and endoscopic gastritis -Kyoto classification of gastritis]. Japanese J Gastroenterol 2015; 112: 982-993

[7] Capelle LG, de Vries AC, Haringsma j et al. The staging of gastritis with the OLGA system by using intestinal metaplasia as an accurate alter- native for atrophic gastritis. Gastrointest Endosc 2010; 71: 11501158

[8] Esposito G, Pimentel-Nunes P, Angeletti S et al. Endoscopic grading of gastric intestinal metaplasia (EGGIM): a multicenter validation study. Endoscopy 2019; 51: 515-521

[9] Kimura K, Takemoto T. An endoscopic recognition of the atrophic border and its significance in chronic gastritis. Endoscopy 1969; 1: 87-97

[10] Lage J, Uedo N, Dinis-Ribeiro M et al. Surveillance of patients with gastric precancerous conditions. Best Pract Res Clin Gastroenterol 2016; 30: 913-922

[11] Dixon MF, Genta RM, Yardley JH et al. Classification and grading of gastritis. The updated Sydney System. International Workshop on the Histopathology of Gastritis, Houston 1994. Am J Surg Pathology 1996; 20: 1161-1181

[12] Kono S, Gotoda T, Yoshida S et al. Can endoscopic atrophy predict histological atrophy? Historical study in United Kingdom and Japan. World J Gastroenterol 2015; 21: 13113-13123

[13] Kanemitsu T, Yao K, Nagahama T et al. Extending magnifying NBI diagnosis of intestinal metaplasia in the stomach: the white opaque substance marker. Endoscopy 2017; 49: 529-535

[14] Uedo N, Ishihara R, lishi $\mathrm{H}$ et al. A new method of diagnosing gastric intestinal metaplasia: narrow-band imaging with magnifying endoscopy. Endoscopy 2006; 38: 819-824 